\title{
Measuring what? A comparative anatomy of five mining sustainability frameworks
}

\author{
Alberto Fonseca ${ }^{\mathrm{a}, *}$, Mary Louise McAllister ${ }^{\mathrm{b}}$, Patricia Fitzpatrick ${ }^{\mathrm{c}}$ \\ ${ }^{a}$ Department of Environmental Engineering, School of Mines, Federal University of Ouro Preto, Morro do Cruzeiro, Ouro Preto, MG 35400-000, Brazil \\ ${ }^{\mathrm{b}}$ Department of Environment and Resource Studies, University of Waterloo, ON, Canada N2L 3G1 \\ ${ }^{\mathrm{c}}$ Department of Geography, University of Winnipeg, Winnipeg, MB, Canada R3B 2E9
}

\section{A R T I C L E I N F O}

\section{Article history:}

Received 22 October 2012

Accepted 9 April 2013

Available online 10 May 2013

\section{Keywords:}

Sustainability assessment

Sustainability reporting

Frameworks

Mining sustainability

Minerals

\begin{abstract}
A B S T R A C T
Recent years have seen a proliferation of frameworks for assessing and reporting mining sustainability. While these frameworks vary substantially in scope and approach, they all seem to share the purported goal of better informing decision-makers about the future implications of mining to the environment and society. Whether they do so, however, remains an open question. The purpose of this paper is to describe, compare and critically analyse five sustainability assessment and reporting frameworks used by, or proposed for, the mining industry. Based on literature reviews, the paper highlights the underlying assumptions of those frameworks and presents a diagram that helps to clarify aspects such as temporal orientation, geographical scope and quantity of indicators. Three out of the five frameworks follow a siloed approach to assessing mining sustainability, overlooking trade-offs and synergies among variables and sustainability dimensions. None of the frameworks seems to fully shed light on the problem of mineral scarcity and the effective legacy of mineral operations. The paper concludes by emphasizing the need to carefully consider the information generated by the analysed frameworks and suggest more fruitful ways to foster sustainability reports.
\end{abstract}

(c) 2013 Elsevier Ltd. All rights reserved.

\section{Introduction: the burgeoning science of measuring mining sustainability}

The public perception of the mining industry remains negative despite the proliferation of mining sustainability initiatives over the past two decades. One analysis that tracked the ethical reputation of multinationals in the media found that basic resources companies, which includes 32 mining and metals multinationals, ranked 17th out of 18 other industrial sectors (Covalence, 2009).

Fuelling this reputational problem is the reality that mining deals with non-renewable resources. It is easy to agree that the social and environmental impacts of mineral extraction need to be harnessed through eco-efficiency, community investments, equitable allocation of mineral rents, and so forth. However, there is little public consensus about how to make the extraction of non-renewable resources compatible with sustainability. Many NGOs have argued that "mining is inherently unsustainable" and that "(...) a truly sustainable global society will take fewer minerals from the earth each year" (Young and Septoff, 2002, p. 1). Yet organizations such as the International Council on Mining and Metals (ICMM) disagree that mining activities should be kept to a minimum, since the sector plays an important role in promoting sustainable development. According to that Council, mining, like any other human

\footnotetext{
* Corresponding author. Tel./fax.: +55 3135591496.

E-mail address: albertof@em.ufop.br (A. Fonseca).
}

activity, should be "undertaken in such a way that the activity itself and the products produced provide a net positive long-term contribution to human and ecosystem well-being" (ICMM, 2012a, p. 5).

The ongoing controversy surrounding the concept of mining sustainability would probably diminish if the "science" of assessing and reporting mining sustainability were sufficiently developed. As environmental engineer Gavin Mudd asked: "How on earth do we really assess the sustainability of mining and move beyond rhetoric and policy to really understand this debate?" (Mudd, 2007, p. 27). Mudd's question awaits an answer. There is no agreement on how to assess mining sustainability, even within similar contexts and unit of analysis.

This knowledge gap has not impeded the development of mining sustainability frameworks. The Global Compendium of Sustainability Indicators Initiatives includes at least 20 records of frameworks that can be used to assess mining sustainability (IISD, 2012). A growing number of similar frameworks are being proposed by scholars as well. Nonetheless, the effectiveness of such initiatives (i.e. their capacity to generate sound information about the future socio-environmental effects of mining) has received very little scrutiny. Petrie et al. (2007, p. 144) examined this problem recently and concluded that "there is little in the public domain, which demonstrates how sustainability metrics and frameworks are actually used to support decision making, and whether better decision outcomes are achieved as a result". 
Readers of the reports generated by mining sustainability frameworks (e.g. consultants, communities, investors, activists) might overlook the limitations of such reports. As scholars often point out, the "selected" indicators and metrics may suggest that the mining company or operational site is "generally" progressing towards sustainability (Moneva et al., 2006; Gray, 2010).

The objective of this paper is to shed light on the burgeoning and confusing practice of assessing and reporting mining sustainability. It does so by describing, comparing and critically analyzing five (5) frameworks used by or proposed for mining companies and industry associations. The underlying purpose is to assess the effectiveness and limitations of such frameworks. Findings from this assessment are particularly useful for communities and institutions interested in the mineral sector's socio-environmental accountability.

\section{Methodology}

The term "Sustainability assessment framework" has been described in several ways, often on an ad hoc basis. Simply put, a framework is a structure composed of components framed together to support something. When used to support sustainability assessment and reporting, it includes "components" such as indicators, conceptual models, principles, criteria, goals, and policies. A framework can be stand alone, or made up of different frameworks, which, in turn, can include other frameworks. This complexity is exacerbated as the frameworks are not always conceptualized or presented with a clear description of the assumptions and preferences taken into account during their design.

The evaluation of the mining sustainability frameworks presented here was based on recent works by Ness et al. (2007) and Hacking and Guthrie (2008). These authors propose techniques to analyze the main attributes of sustainability frameworks, in order to help clarify the assumptions of, and consequent confusion surrounding, the sustainability information generated. Ness et al. (2007) developed a two-dimensional diagram that classifies frameworks horizontally according to their temporal focus (retrospective or prospective) and vertically according to the types of indicators and/or spatial focus. Hacking and Guthrie (2008), for their part, developed a three-dimensional diagram to understand the differences among various sustainability frameworks in the context of impact assessment. These authors devised a cube with three axes. Each axis corresponded to degrees of either (a) comprehensiveness of social and environmental topics or indicators; (b) the scale and scope of assessment, i.e. the degree to which frameworks consider geographical scale variations; and (c) integration, i.e. the extent to which frameworks evaluate trade-offs and synergies among sustainability topics or indicators.

This paper draws from these approaches by creating a twodimensional diagram, similar to that proposed by Ness et al. (2007). However, it includes variables considered by both approaches, including: (a) temporal orientation; (b) geographical focus; (c) comprehensiveness; (d) integration (trade-offs and synergies); and (e) scale and scope considerations. Each sustainability framework is plotted horizontally according to its temporal orientation and vertically according to its degrees of indicator/ topic integration. Degrees of comprehensiveness are described qualitatively through the size of the sphere of the framework in the diagram: the larger the sphere, the higher the quantity of sustainability indicators/topics. Geographical foci and considerations of scale are not displayed in the diagram although they are evaluated and discussed.

Given the proliferation of sustainability frameworks, this research employed a purposive sampling approach (Babbie, 2010), i.e. the sample was selected on the basis the of the authors' judgment about which cases would best represent the frameworks used by, or proposed, for mining companies, particularly large ones. Two of the five selected mining sustainability frameworks, the Global Reporting Initiative (GRI) and the Toward Sustainable Mining (TSM), are among the most frequently used by large mining companies, particularly in Canada. The other three frameworks seven questions to sustainability (7QS), innovation and technology driven sustainability performance management framework (ITSPM) and Adisa Azapagic's - were proposed by analysts and academics, but arguably resulted in little or no implementation on the ground. These cases reflect a range of approaches used to assess and report mining sustainability. Although it is limited, the sample allows for an initial glimpse into the emerging practice of measuring mining sustainability.

The analysis is based on the evaluation of the five frameworks' documents (e.g. protocols, principles, and progress reports, etc.), as well as on secondary academic and grey literature. The frameworks are analysed individually in the sub-sections below. Further discussion and synthesis are presented in the following section.

\section{Results: mining sustainability frameworks in the disassembly line}

\subsection{Global reporting initiative and the mining and metals sector supplement (GRI-MMSS)}

The GRI framework (GRI, 2011) and its mining and metals sector supplement (MMSS) (GRI, 2010) is arguably the most widely adopted sustainability framework in the mining sector. The year 2011 witnessed the publication of 102 reports from mining companies, 95\% of which based on the GRI framework (GRI, 2012). Several global and national mining associations adopt and promote the GRI framework among its members (ICMM, 2012b; MCA, 2010; WGC, 2010). The GRI framework has its roots in the accountability field. It was first piloted in the late 1990s and is now in its third version, known as the GRI G3.1 (GRI, 2011). This version is made up of several guidance documents providing guidance on "how to report" and "what to report", described as follows (GRI, 2010):

- Reporting Guidelines: The guidelines are the cornerstone of the GRI G3. They set quality and content principles, as well as managerial and performance indicators. The principles for defining content include materiality, stakeholder inclusiveness, sustainability context, and completeness. The indicators (about 130) cover several thematic categories, including organizational, managerial, economic, environmental, social, human rights, society, and product responsibility issues;

- Sector Supplements: The supplements provide additional guidance and indicators for sector specific issues. One of the supplements is the aforementioned mining and metals sector supplement; and

- Indicator Protocols: The protocols provide definitions and technical and methodological guidance on each of the performance indicators of the guidelines.

The framework's temporal orientation follows a retrospective logic, although in an implicit manner (Lenzen et al., 2004). The GRI-MMSS guides mining companies to assess and report "past year" performance in connection with various social, environmental and economic indicators.

The framework is notable for its comprehensiveness. It presents over 150 indicators of various types. Companies are encouraged to assess and report on the most material indicators. A GRI G3.1 report is not expect to bring information on all indicators, but only 
on the core ones, as perceived by the companies' consulted stakeholders.

Although seemingly comprehensive in detail, one of the most notable oversights of this framework is its lack of geographical or spatial focus. GRI-MMSS is organizationally-centred, similar to the financial reporting frameworks. Mining companies are required to assess and report on the performance of the "organization" instead of "mining sites" or regions. These requirements have been virtually absent in practice, although the framework purports to require companies to take into consideration boundaries and spatial context. One possible explanation is that the framework protocols provide very little technical guidance on how to contextualize the assessment (McElroy et al., 2008).

Furthermore, the GRI framework follows a "siloed" approach by considering the various indicators in isolation. The many trade-offs and synergies among sustainability dimensions are largely overlooked in the framework (Milne et al., 2008; Moneva et al., 2006). This is also the case with respect to considerations of scale, i.e. how performance varies across local, regional, national and global scales.

\subsection{Azapagic's sustainable development framework for the mining and metals industry}

Environmental engineer Adisa Azapagic developed an "enhanced" framework for mining companies (Azapagic, 2004). Her framework, proposed in 2003, is an expanded, mining-centred version of the second generation of the GRI framework (known as GRI G2). At that time, GRI had not launched sector-specific indicators (i.e. MMSS). Azapagic's work has been cited by nearly 100 articles on the Scopus Database (2013) and over 200 hundreds on Google Scholar (2013). Her proposed framework is one of the most influential in mining-related research. Nonetheless, few, if any, companies currently adopt Azapagic's recommendations. This is, in part, due to the fact that her proposal was based on the out-of-date GRI G2.

Azapagic's proposed framework, as a GRI-based framework, shares the following characteristics with the current GRI G3.1, namely: (a) retrospective temporal orientation; (b) lack of spatial/geographical foci requirements; and (c) organizationallycentred indicators. Nonetheless, Azapagic's work is more comprehensive insofar as it enforces reporting on "all" 140 indicators (recall the GRI guides reporting on the most "material" ones). Moreover, to a certain extent, her framework is more integrative, as it includes several indicators that link social, environmental and economic aspects. This difference mirrors the fact that, at the time Azapagic developed her work, the GRI G2 framework encouraged organizations to develop integrated measures. Such a requirement has been dismissed in the GRI G3 version.

The integrated indicators in Azapagic's framework include wealth created expressed as profit per employee; environmental impacts per mass of product sold; and, energy consumption per mass of product sold. These indicators, however, do not seem to offer a thorough understanding of the potential trade-offs and synergies among the many sustainability dimensions affected by mining operations. Furthermore, although the integration covers internal indicators, no attention is given to how internal performance relates to the external environment.

Although Azapagic created a framework that employs a wide range of indicators, she recognizes that they cannot be aggregated into an overall index indicative of "sustainable development". She also recognizes that the framework "may be more suitable for large-scale mining and larger organizations, which could afford the time and resources for its implementation" (Azapagic, 2004, p. 660).
3.3. Innovation and technology driven sustainability performance management framework (ITSPM) by Arun Basu and Uday Kumar

Environmental scientists Basu and Kumar (2004) also proposed a sustainability framework for the mining sector, named innovation and technology driven sustainability performance management (ITSPM). Their proposed framework, while not as widely cited as Azapagic's, has some noteworthy features. This is particularly the case with respect to the emphasis on the roles that governance, innovation and technology perform in enabling sustainability performance improvements at the site level.

Unlike the two frameworks above, ITSPM is essentially conceptual in orientation. It defines broad pillars of performance (social, environmental, economic) and foundation areas (multi-stakeholder governance, technology, innovation) that should support sustainability goals, but without specific details as to types and quantity of indicators. Neither criteria for pillar integration nor considerations of scales are included in the framework. The ITSPM resembles the GRI-MMSS framework in its embryonic stages. Further elaboration of its elements is unlikely to yield meaningful innovation in the area of framework design.

Both the ITSPM and Azapagic's work constitute examples of "theoretical" frameworks. While not adopted by mining companies, these frameworks broaden the repertoire of techniques for measuring mining sustainability in the sector. ITSPM calls for a more robust treatment of innovation and technology in the assessment process; Azapagic's call for integrated, quantifiable organizational metrics.

\subsection{Mining association of Canada's towards sustainable mining (TSM)}

In the early 2000s, the Mining Association of Canada (MAC) developed a different approach to measuring sustainable development in the mining industry: towards sustainable mining (TSM). Publicly launched in May 2004, the TSM constitutes an evolving set of guiding principles and performance indicators in key areas. TSM shares GRI's retrospective temporal orientation and lack of integration and scale considerations, but displays significant differences in terms of quantity of indicators (comprehensiveness) and geographical focus.

TSM includes a set of 18 indicators across six categories (tailings management; energy use and GHG emissions management; aboriginal and community outreach; crisis management planning; biodiversity conservation management; and safety and health) (MAC, 2012). In focusing on six categories, TSM misses potentially relevant sustainability issues. The benefit of such a narrow approach, however, is that it promotes more reliable and comparable performance results (Fitzpatrick et al., 2011). In 2005, the Globe Foundation awarded MAC the Industry Association Award for Environmental Performance, acknowledging that this association had "shown leadership by going beyond regulatory compliance to develop a collective commitment to improved environmental performance through research, development and education in partnership with governments, non-governmental organizations, communities and other stakeholders" (MAC, 2005).

Another relevant aspect of TSM is its clear focus on "site level" performance. TSM was designed to help operational sites improve their internal performance. In adopting such a clear spatial focus of analysis, TSM lessens the challenge of dealing with contextual data from outside the companies' boundaries. A key benefit of this approach is that the resulting TSM reports, unlike GRI's, carries more objective, quantifiable data that can be consistently aggregated into sector-wide reports. The MAC periodically publishes TSM reports carrying information from all complying Canadian mining companies. Currently available data (published annually between 2005 and 2012) provide a fair understanding of how each company 
member and the overall group are improving on particular indicators. Such indicators, however, do not give any sense of whether companies are progressing or not towards the "general" goal of sustainability.

\subsection{Seven questions to sustainability ( $7 Q S)$}

The seven questions to sustainability (7QS) is one of the main outcomes of the Mining, Minerals, and Sustainable Development research project. The North American branch of this project was responsible for developing an approach to assessing contributions of mineral projects to sustainability. The result was an integrated and future-oriented framework known as 7QS (MMSD, 2002).

The 7QS guides decision-makers to answer questions in connection with seven themes: (1) engagement; (2) people; (3) environment; (4) economy; (5) traditional and non-market activities; (6) institutional arrangements and governance; and (7) synthesis and continuous learning. The framework requires decision-makers to define ideal answers to each of the seven questions, as well as specific indicators and metrics for those answers. The 7QS, however, is not as specific as GRI G3.1 and TSM. Its indicators and metrics are to be defined on a case-by-case basis. The $7 Q S$ is a " (..) starting point set of considerations (...) not the decision-making process itself" (MMSD, 2002, p. 3). The 7QS "frames" the decision-making process amid those seven questions, but leaves to the stakeholders numerous decisions in connection with quantity and types of indicators, means and degrees of public participation, criteria for comparing impacts, third-party audit, among others.

The $7 Q S$ has a clear spatial focus. It applies to mining projects (proposed or in operation). Nonetheless, the $7 \mathrm{QS}$ includes little or no consideration of scale effects. The framework does have a more sophisticated treatment of time, as the seven questions apply to the life cycle of the mine, spanning exploration through postclosure phases. This prospective approach enables a better understanding of legacy effects, which are one of the most critical in the mining sector. The $7 \mathrm{QS}$ also guides decision-makers to analyze trade-offs and synergies through its seventh area of questioning: Does a full synthesis show that the net result will be positive or negative in the long term? No guidance, however, is provided to the challenging process of comparing the relative values of mining projects' numerous social and environmental impacts.

In 2007, the practical value of the 7QS was corroborated by the Joint Panel Review of the impact assessment of the proposed expansion of the Kemess gold-copper mine in Canada. The panel adopted a somewhat innovative framework to evaluate the proposed mining project, which was based on the 7QS (Fonseca and Gibson, 2008). The panel's framework had five, instead of seven, areas of questioning. It included environmental stewardship; economic benefits and costs; social and cultural benefits costs; fair distribution of benefits and costs; present versus future generations (Jones et al., 2007). Unfortunately, this is one of the few examples of the framework's application. In a GRI-dominated sector, the $7 Q S$ appears more like a historical rather than alternative technique of mining sustainability assessment.

\subsection{Categorising mining sustainability frameworks}

The main findings are synthesized in Table 1 . In spite of their simplicity, these findings reveal interesting patterns. For example, four out of the five frameworks had a clear retrospective temporal focus. Two frameworks were essentially non-integrative, following a "siloed" approach while overlooking trade-offs and synergies among sustainability issues. None included considerations of scale across local, regional and more global levels, a gap that has been pointed out in previous research (Giurco and Cooper, 2012).
The differences between frameworks can also be seen in the diagram presented in Fig. 1, which is based on the aforementioned works of Ness et al. (2007) and Hacking and Guthrie (2008). The diagram presents boxes indicating categories of frameworks, and plots, with circles, the five frameworks reviewed here.

\section{Discussion}

The diagram in Fig. 1 highlights not only some of the key features of the reviewed frameworks, it also highlights several other categories or "types" of frameworks that may inform future framework design in the mining sector. Scholarship in the fields of sustainability assessment (e.g. Hodge, 2006; IISD and OECD, 2010) suggests that a one-size-fits-all approach is unlikely to emerge any time soon. It is necessary to have experimentation with timeframes, integration, life cycle thinking and system dynamics, among others. Sustainability assessment, while a relatively new science, has already indicated a plethora of avenues to be explored (Bebbington et al., 2007; Diesendorf, 2001; Frame and Cavanagh, 2009; Grame and O'Connor, 2011; Moran et al., 2008; Singh et al., 2009).

Mining stakeholders also need to be aware of the effective role of current frameworks. The well-known GRI approach, for example, is inherently limited. The framework focuses excessively on organizational data drawn from the past year's performance of a company, rather than on trying to understand the future implications of mining operations to the sustainability of ecosystems and communities on the ground. Improvement in its potential to generate meaningful information about mining sustainability is not just a matter of including or excluding indicators. To be more effective and informative, the framework requires further elaboration of time and scale framing.

Only two frameworks of those presented above seemed to mirror a more systemic perspective. As discussed above, Azapagic provides a preliminary attempt, but by no means can capture the necessary trade-offs and synergies among indicators. The $7 \mathrm{QS}$, while more integrative and prospective, lacks specific and transparent metrics, a gap that may generate mistrust and confusion among decision-makers.

One of the most interesting aspects about the frameworks discussed above is that they all appear to downplay the problem of scarcity of (proven) mineral reserves, particularly at the global level. The controversial issue of mineral non-renewability and scarcity, which has been increasingly discussed since the publication of The Limits to Growth (Meadows et al., 1992, 1972, 2004), is addressed in an elusive or limited way. The GRI and Azapagic's frameworks guide companies to measure and report input of recycle materials as well as their managerial approach to material stewardship. The TSM and the ITSPM frameworks do not include indicators directly related to mineral stocks, materials flow, and recycling, etc. The metrics of these four frameworks focus mainly on the eco-efficiency of mining operations, which, as Paul Hawken et al. (1999) note, is only one small part of a web of solutions needed in sustainable systems. The $7 \mathrm{QS}$ go beyond eco-efficiency while requiring decision-makers to consider legacy effects, i.e. the extent to which the extraction of minerals at the mining site translate into net positive gains to the environment and affected communities. In doing so, the 7QS is aligned with the concept of "weak sustainability", define by Pearce and Atkinson (1993) as a type of sustainability in which the overall capital stock (renewable, non-renewable, man-made, and cultural, etc.) is non-decreasing. Such an approach is disputed by many scholars, who prefer a stronger approach, in which certain stocks of "critical" capitals (e.g. non-renewables) should not be substituted or decreased (Gutés, 1996). 
Table 1

A comparative anatomy of the five sustainable mining frameworks.

\begin{tabular}{|c|c|c|c|c|c|}
\hline Characteristics & GRI G3.1 & Azapagic's & ITSPM & TSM & $7 Q S$ \\
\hline Usage & $\begin{array}{l}\text { Used by dozens of the world's } \\
\text { largest mining companies }\end{array}$ & $\begin{array}{l}\text { Conceptual/theoretical } \\
\text { proposal }\end{array}$ & $\begin{array}{l}\text { Conceptual/ } \\
\text { theoretical } \\
\text { proposal }\end{array}$ & $\begin{array}{l}\text { Used by } \\
\text { Canada's } \\
\text { largest mining } \\
\text { companies }\end{array}$ & $\begin{array}{l}\text { Conceptual/theoretical proposal of the } \\
\text { MMSD Project }\end{array}$ \\
\hline $\begin{array}{l}\text { Temporal } \\
\text { orientation }\end{array}$ & Retrospective (past year) & $\begin{array}{l}\text { Retrospective (past } \\
\text { year) }\end{array}$ & Retrospective & $\begin{array}{l}\text { Retrospective } \\
\text { (past year) }\end{array}$ & Prospective (mine life cycle) \\
\hline $\begin{array}{l}\text { Spatial or } \\
\text { geographical } \\
\text { focus }\end{array}$ & $\begin{array}{l}\text { Organizational-centred. } \\
\text { Unclear spatial boundaries and } \\
\text { criteria for aggregating data } \\
\text { from multiple sites }\end{array}$ & Organizational-centred & $\begin{array}{l}\text { Mining site } \\
\text { (operating) }\end{array}$ & $\begin{array}{l}\text { Mining site } \\
\text { (operating) }\end{array}$ & Mining site (project or operating) \\
\hline $\begin{array}{l}\text { Comprehensiveness } \\
\text { (quantity of } \\
\text { indicators/topics) }\end{array}$ & $\begin{array}{l}\text { Quantity of assessed/described } \\
\text { topics or indicators, may vary } \\
\text { from just a few to almost } 200 \text {, } \\
\text { across several categories }\end{array}$ & $\begin{array}{l}140 \text { indicators, across } \\
\text { several categories }\end{array}$ & $\begin{array}{l}\text { Unclear, but } \\
\text { covering social, } \\
\text { environmental, } \\
\text { and economic } \\
\text { categories }\end{array}$ & $\begin{array}{l}18 \text { indicators } \\
\text { across } 6 \\
\text { categories }\end{array}$ & $\begin{array}{l}\text { Not specified, but focused on seven } \\
\text { dimensions }\end{array}$ \\
\hline $\begin{array}{l}\text { Integration ( } \text { silos } \\
\text { versus system) }\end{array}$ & Overlooked & $\begin{array}{l}\text { Some consideration for } \\
\text { relationships among } \\
\text { social, economic and } \\
\text { environmental impacts }\end{array}$ & Overlooked & Overlooked & Considered, but poorly specified \\
\hline Scale effects & Overlooked & Overlooked & Overlooked & Overlooked & Overlooked \\
\hline $\begin{array}{l}\text { Definition of } \\
\text { sustainability }\end{array}$ & $\begin{array}{l}\text { Based on the our common } \\
\text { future report (WCED, 1987) }\end{array}$ & $\begin{array}{l}\text { Based on the our } \\
\text { common future report } \\
\text { (WCED, 1987) and } \\
\text { findings of the MMSD } \\
\text { project }\end{array}$ & $\begin{array}{l}\text { Based on our } \\
\text { common future } \\
\text { report (WCED, } \\
\text { 1987) }\end{array}$ & $\begin{array}{l}\text { Based on the } \\
\text { our common } \\
\text { future report } \\
\text { (WCED, 1987) }\end{array}$ & $\begin{array}{l}\text { Unique conceptual interpretations, such as: } \\
\text { sustainability "( } . .) \text { is much more than } \\
\text { environmental protection in another guise. } \\
\text { It is a positive concept that has as much to } \\
\text { do with achieving wellbeing for people and } \\
\text { ecosystems as it has to do with reducing } \\
\text { stress or impacts." (2002, p. } 7 \text { ) }\end{array}$ \\
\hline
\end{tabular}

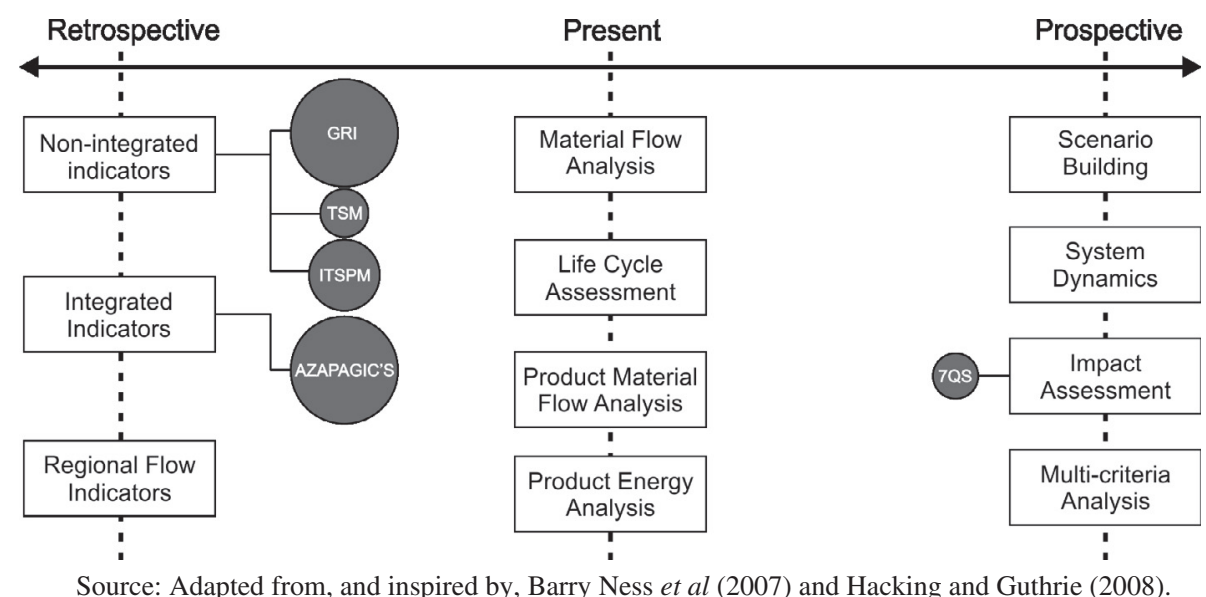

Fig. 1. Categories of mining sustainability frameworks.

None of the frameworks analysed here guide decision-makers to systematically consider changes of minerals stocks in the ground, let alone across geographical scales. What seems to be driving those frameworks is less the need to preserve minerals to future generations and more the need to ensure performance improvements in connection with some environmental, social and economic areas. With the exception of the ITSPM and the GRI, the frameworks do not emphasize the important roles of mineral recycling and technology innovation in promoting sustainability.

In light of the obvious limitations of current frameworks, scholars are continuously proposing new approaches to assessing and reporting mining sustainability. For example, Worrall et al. (2009) proposed a unique indicator framework to measure progress towards sustainability in the context of legacy mined land. Jin Yu et al. (2005) developed a framework applicable to mining cities in China. Joseph Fiksel (2006) proposed a systems-based framework that is supposed to capture the flows of materials (including minerals) across the globe, thus revealing whether nations' material consumption is being decoupled from economic value creation. Tracy Lydiatt et al. (2008) proposed the application of The Natural Step (TNS) framework to mining projects. The TNS framework, developed by the cancer scientist Robèrt (2000), has a principle that is apparently incompatible with mineral development, i.e. that the concentrations of substances extracted from the Earth's socio-ecological systems should not systematically increase. Numerous other examples of sustainability frameworks applicable to the mineral sector are presented in global conferences, such as the Sustainable Development Indicators in the Minerals Industry, held bi-annually since 2003 (SDIMI, 2013).

In spite of the multiplication of mining sustainability frameworks, the scholarship still seems to lack a sense of the desirable principles to be observed in the design of measurement and reporting systems. Four out of the five frameworks analysed here, while explicitly endorsing the famous definition of sustainable developed coined by the Our Common Future report (WCED, 1987), drew their 
Table 2

Current versus desirable approach to gri-based sustainability reporting according to the BellagioSTAMP principles. Source: Fonseca et al. (2013)

\begin{tabular}{|c|c|c|}
\hline $\begin{array}{l}\text { Framework } \\
\text { assessment and } \\
\text { reporting aspects }\end{array}$ & $\begin{array}{l}\text { Current GRI-based } \\
\text { approach }\end{array}$ & Desirable approach \\
\hline Guiding vision & $\begin{array}{l}\text { Sustainability, overlooking } \\
\text { the need to operate within } \\
\text { the capacity of the } \\
\text { biosphere }\end{array}$ & $\begin{array}{l}\text { Sustainability, respecting } \\
\text { the need to operate within } \\
\text { the capacity of the } \\
\text { biosphere }\end{array}$ \\
\hline $\begin{array}{l}\text { Conceptual } \\
\text { framework }\end{array}$ & $\begin{array}{l}\text { Tacit, non-systemic and } \\
\text { issues-based }\end{array}$ & $\begin{array}{l}\text { Explicit, geographically- } \\
\text { based and scale-based }\end{array}$ \\
\hline $\begin{array}{l}\text { Evaluation of } \\
\text { trade-offs and } \\
\text { synergies } \\
\text { within and } \\
\text { across systems }\end{array}$ & Overlooked & $\begin{array}{l}\text { Assessed, justified, and } \\
\text { explained }\end{array}$ \\
\hline $\begin{array}{l}\text { Geographical } \\
\text { scope }\end{array}$ & Weakly addressed & $\begin{array}{l}\text { Implemented from local to } \\
\text { global (facility level, } \\
\text { regional/national-level, } \\
\text { and global level reports) }\end{array}$ \\
\hline $\begin{array}{l}\text { Temporal } \\
\text { orientation }\end{array}$ & $\begin{array}{l}\text { Predominantly } \\
\text { retrospective }\end{array}$ & $\begin{array}{l}\text { Retrospective and } \\
\text { prospective, with scenario } \\
\text { building or forecasting/ } \\
\text { backcasting techniques, } \\
\text { allowing understanding of } \\
\text { legacy effects }\end{array}$ \\
\hline Types of indicators & $\begin{array}{l}\text { Non-integrated, mostly } \\
\text { pressure and response }\end{array}$ & $\begin{array}{l}\text { Non-integrated and } \\
\text { integrated, addressing } \\
\text { pressure, state, and } \\
\text { response, as well as } \\
\text { relationships among them }\end{array}$ \\
\hline $\begin{array}{l}\text { Disclosures of } \\
\text { assumptions } \\
\text { and } \\
\text { uncertainties }\end{array}$ & Limited & Thorough \\
\hline
\end{tabular}

indicators, protocols, policies and principles from different bodies of literature. It is safe to argue that the different approaches to measuring sustainability in the analysed sample are not a result of conflicting definitions of sustainability, but of conflicting principles and assumptions on how to measure it.

Few institutions or scholars have attempted to develop principles on sustainability assessment and reporting. A notable exception is the "Bellagio Principles for Sustainability Assessment principles". The Bellagio Principles are not yet another framework; rather, they constitute a set of generic principles that can be used to design new frameworks. The first version of the Bellagio Principles included 10 principles that were unanimously endorsed in Bellagio, Italy, in 1996. These principles were revised in 2009 by the IISD and OECD to become more influential and concise, while reflecting the newest scientific and political context. The newest version includes eight principles, concisely known as BellagioSTAMP, which includes various requirements within the following categories: (1) guiding vision; (2) essential considerations; (3) adequate scope; (4) framework and indicators; (5) transparency; (6) effective communication; (7) broad participation; and (8) continuity and capacity (IISD and OECD, 2010).

Recently, Fonseca et al. (2013) used the BellagioSTAMP principles 1-4 to evaluate the "soundness" of the GRI G3 framework and its mining and metals sector supplement. Their main findings can be seen in Table 2 .

Fonseca et al. (2013) conclude that the GRI approach to assessing and communicating mining contributions to sustainability has gaps within each of the analyzed BellagioSTAMP principles. Filling those gaps would demand, at a minimum, a more systematic consideration of site-level performance, scenario building, and legacy effects in the framework. Nonetheless, it is important to note that the BellagioSTAMP principles were not designed specifically for the mining context. Authors from different backgrounds, when adopting the same principles, might have different interpretations on their practical implications, thus achieving different results.

The BellagioSTAMP principles are important, but not nearly sufficient for the purpose of settling the debate around mining sustainability metrics. Today, mining companies genuinely interested in understanding their potential contributions to sustainability have no other choice but to adopt a combination of assessment frameworks. Such a combination, however, will not reveal an overall sense of sustainability, but fragmented (and likely contestable) information that can only be useful in specific contexts.

\section{Conclusions}

This paper described, compared and analysed five mining sustainability assessment and reporting frameworks used by or proposed for companies and industry associations. Four out of the five analysed frameworks were found to follow a predominately retrospective siloed approach to assessing mining sustainability, while overlooking trade-offs and synergies among sustainability dimensions. None of the frameworks seemed fully capable of shedding light on the problem of scarcity of mineral resources and the effective legacy of mineral operations across geographical scales. Overall, the paper highlights the value of further researching and developing mining sustainability assessment frameworks.

Future studies should analyse and compare other frameworks, based on more specific criteria and diagrams, making evident additional limitations and implications of current designs. Most importantly, future studies should try to understand how best to treat time, space, scales, indicators, among other elements, in the design of frameworks, thus generating measurement and reporting knowledge to the mining sector. As discussed above, the BellagioSTAMP principles, while valuable, are too generic; their implications to the assessment of mining operations may be interpreted in various ways by stakeholders. Without a set of sector-specific measurement principles, it will be hard to dispute the oxymoronic nature of the expression "sustainable mining" and demonstrate the long-term viability of mineral extraction at the site, regional and global levels.

\section{Acknowledgement}

The authors would like to thank the Social Sciences and Humanities Research Council (SSHRC) for the financial support to this research.

\section{References}

Azapagic, A., 2004. Developing a framework for sustainable development indicators for the mining and minerals industry. Journal of Cleaner Production 12, 639662 .

Babbie, E., 2010. The Practice of Social Research, 10th ed. Wadsworth/Thomson Learning, Belmont, CA.

Basu, A.J., Kumar, U., 2004. Innovation and technology driven sustainability performance management framework (ITSPM) for the mining and minerals sector. International Journal of Mining, Reclamation and Environment 18, 135149 .

Bebbington, J., Brown, J., Frame, B., 2007. Accounting technologies and sustainability assessment models. Ecological Economics 61, 224-236.

Covalence, 2009. Mining \& Metals Face Growing Ethical Claims - Covalence Basic Resources Sector Report 2009. <http://www.covalence.ch/index.php/2009/ 08/31/mining-metals-face-growing-ethical-claims-covalence-basic-resourcessector-report-2009> (accessed 02.02.10).

Diesendorf, M., 2001. Models of sustainability and sustainable development. International Journal of Agricultural Resources, Governance and Ecology 1, 109-123.

Fiksel, J., 2006. A framework for sustainable materials management. JOM - Journal of the Minerals, Metals and Materials Society 58, 15-22. 
Fitzpatrick, P., Fonseca, A., McAllister, M.L., 2011. From the Whitehorse mining initiative towards sustainable mining. Journal of Cleaner Production 19, 376384.

Fonseca, A., Gibson, R.B., 2008. Application denied: BC's Kemess North and Nova Scotia's whites point projects promised jobs and revenue, but the communities were looking for overall sustainability. Alternatives Journal $34,10-12$.

Fonseca, A., McAllister, M.L., Fitzpatrick, P., 2013. Sustainability reporting among mining corporations: a constructive critique of the GRI approach. Journal of Cleaner Production. http://dx.doi.org/10.1016/j.bbr.2011.03.031.

Frame, B., Cavanagh, J., 2009. Experiences of sustainability assessment: an awkward adolescence. Accounting Forum 33, 195-208.

Giurco, D., Cooper, C., 2012. Mining and sustainability: asking the right questions. Minerals Engineering 29, 3-12.

Grame, B., O'Connor, M., 2011. Integrating valuation and deliberation: the purposes of sustainability assessment. Environmental Science \& Policy 14, 1-10.

Gray, R., 2010. Is accounting for sustainability actually accounting for sustainability... and how would we know? An exploration of narratives of organisations and the planet. Accounting, Organizations and Society 35, 47-62.

GRI, 2010. Sustainability Reporting Guidelines \& Mining and Metals Sector Supplement. Global Reporting Initiative, Amsterdam.

GRI, 2011. Sustainability Reporting Guidelines - Version 3.1. Global Reporting Initiative (GRI), Amsterdam.

GRI, 2012. GRI Sustainability Disclosure Database. Global Reporting Initiative (GRI), Amsterdam.

Gutés, M.C., 1996. The concept of weak sustainability. Ecological Economics 17, 147-156.

Hacking, T., Guthrie, P., 2008. A framework for clarifying the meaning of triple bottom-line integrated, and sustainability assessment. Environmental Impact Assessment Review 28, 73-89.

Hawken, P., Lovins, A., Lovins, L.H., 1999. Natural capitalism: creating the next industrial revolution. Little, Brown and Company, London.

Hodge, R.A., 2006. Tracking progress toward sustainability: linking the power of measurement and story. Mining Engineering 58, 63-68.

ICMM, 2012a. Our Work: Sustainable Development Framework. International Council on Mining and Metals, London, <http://www.icmm.com/our-work/ sustainable-development-framework > (accessed 07.10.12).

ICMM, 2012. Mining's Contribution to Sustainable Development. International Council on Mining and Metals (ICMM), London.

IISD, 2012. Compendium: A Global Directory to Indicator Initiatives. International Institute for Sustainable Development, <http://www.iisd.org/measure/ compendium/> (accessed 07.30.12).

IISD, OECD, 2010. BellagioSTAMP: Sustainability Assessment and Measurement Principles. International Institute for Sustainable Development and Organisation for Economic Co-operation and Development, Winnipeg.

Jones, C., Scoble, M., Duiven, M. Kemess North Copper-Gold Mine Project Joint Review Panel Report. Kemess North Mine Joint Review Panel, Vancouver, 2007.

Lenzen, M., Dey, C.J., Murray, S.A., 2004. Historical accountability and cumulative impacts: the treatment of time in corporate sustainability reporting. Ecological Economics 51, 237-250.

Lydiatt, T., Mesquita, P.L., Nolan, A. Sustainable mining? Applying the framework for strategic sustainable development to mining projects. School of Engineering, Blekinge Institute of Technology, Karlskrona, Sweden, 2008.

MAC, 2005. The mining association of Canada receives globe award for environmental performance. <http://www.miningworks.mining.ca/miningworks/ media_lib/documents/News_Releases/globe-award.pdf> (accessed 07.10.12)

MAC, 2012. Towards Sustainable Mining: Progress Report 2011. Mining Association of Canada, MAC.
MCA, 2010. Minerals Council of Australia: What is Enduring Value?. <http:// www.minerals.org.au/enduringvalue/enduring_value/index.html> (accessed 01.10.10).

McElroy, M.W., Jorna, R.J., Engelen, J.v., 2008. Sustainability quotients and the social footprint. Corporate Social Responsibility and Environmental Management 15, 223-234.

Meadows, D.H., Meadows, D.L., Randers III, J., Behrens, W.W., 1972. The Limits to growth: A Report for the Club of Rome's Project on the Predicament of Mankind. Universe Books, New York.

Meadows, D.H., Meadows, D.L., Randers, J., 1992. Beyond the limits: confroting global collapse, envisioning a sustainable future. Chelsea Green Pub. Co., Post Mills, VT.

Meadows, D.H., Randers, J., Meadows, D., 2004. Limits to Growth: The 30 Year Update. Earthscan, London.

Milne, M.J., Ball, A., Gray, R. Wither Ecology? The Triple Bottom Line, the Global Reporting Initiative, and the Institutionalization of Corporate Sustainability Reporting, American Accounting Association, Anaheim, 2008.

MMSD, 2002. Seven Questions to Sustainability: How to Assess the Contributions of Mining and Minerals Activities. IISD, MMSD, WBCSD, Manitoba.

Moneva, J.M., Archel, P., Correa, C., 2006. GRI and the camouflaging of corporate unsustainability. Accounting Forum 30, 121-137.

Moran, D.D., Wackernagel, M., Kitzes, J.A., Goldfinger, S.H., Boutaud, A., 2008 Measuring sustainable development - nation by nation. Ecological Economics 64, 470-474.

Mudd, G., 2007. Sustainable mining - an oxymoron? The Chemical Engineer (TCE). December 2007/Jan 2008, pp. 27-29.

Ness, B., Urbel-Piirsalu, E., Anderberg, S., Olsson, L., 2007. Categorising tools for sustainability assessment. Ecological Economics 60, 498-508.

Pearce, D.W., Atkinson, G.D., 1993. Capital theory and the measurement of sustainable development: an indicator of "weak" sustainability. Ecological Economics 8, 103-108.

Petrie, J., Cohen, B., Stewart, M., 2007. Decision support frameworks and metrics for sustainable development of minerals and metals. Clean Technologies and Environmental Policy 9, 133-145.

Robèrt, K.-H., 2000. Tools and concepts for sustainable development, how do they relate to a general framework for sustainable development, and to each other? Journal of Cleaner Production 8, 243-254.

Google Scholar, 2013. Google Scholar. <http://scholar.google.com.br/schhp> (accessed 02.10.13).

Scopus, 2013. Scopus Document Search. <http://www.scopus.com/home > (accessed 01.20.13).

SDIMI, 2013. International Forum for Sustainable Development Indicators in the Minerals Industry. <http://www.sdimi.org/index.html> (accessed 01.20.13).

Singh, R.K., Murty, H.R., Gupta, S.K., Dikshit, A.K., 2009. An overview of sustainability assessment methodologies. Ecological Indicators 9, 189-212.

WCED, 1987. Our Common Future. Oxford University Press, New York and Oxford

WGC, 2010. World Gold Council Support of the ICMM Principles. <http:/ www.gold.org/assets/file/pub_archive/pdf/wgc_support_of_ICMM_principles. pdf> (accessed 01.10.10)

Worrall, R., Neil, D., Brereton, D., Mulligan, D., 2009. Towards a sustainability criteria and indicators framework for legacy mine land. Journal of Cleaner Production 17, 1426-1434.

Young, J., Septoff, A., 2002. Digging for change: towards a responsible minerals future. An NGO and community perspective. Mineral Policy Centre. <http:// www.rosiamontana.ro/img_upload/472936e3bca2bc61045730fbb1869240/ diggingforChange.pdf> (accessed 25.04.2013).

Yu, J., Yao, S., Chen, R., Zhu, K., Yu, L., 2005. A quantitative integrated evaluation of sustainable development of mineral resources of a mining city: a case study of Huangshi. Eastern China Resources Policy 30, 7-19. 